\title{
COMMENTARY
}

\section{Prerequisite Courses: Barriers to Pharmacy Admission or the Keys to Student Success?}

\author{
Renae Chesnut, EdD, MBA, ${ }^{\mathrm{a}}$ Grant W. Anderson, PhD, ${ }^{\mathrm{b}}$ Olivia Buncher, MA, ${ }^{\mathrm{b}}$ Michael A. Dietrich, PharmD, ${ }^{\mathrm{c}}$
} Jennifer M. Rosenberg, PhD, ${ }^{\mathrm{d}}$ Libby J. Ross, MA ${ }^{\mathrm{e}}$

${ }^{\text {a }}$ Drake University, College of Pharmacy \& Health Sciences, Des Moines, Iowa

${ }^{\mathrm{b}}$ University of Minnesota, College of Pharmacy, Duluth, Minnesota

${ }^{\mathrm{c}}$ Midwestern University, College of Pharmacy, Glendale, Arizona

${ }^{\mathrm{d}}$ University at Buffalo, School of Pharmacy and Pharmaceutical Sciences, Buffalo, New York

${ }^{\mathrm{e}}$ American Association of Colleges of Pharmacy, Arlington, Virginia

Corresponding Author: Libby J. Ross, American Association of Colleges of Pharmacy, 1400 Crystal Dr., Suite 300, Arlington, VA 22202. Tel: 703-479-3809. Email: Lross@ aacp.org.

Submitted October 18, 2021; accepted February 11, 2022; ePublished February 2022

The variability and complexity of course prerequisites across colleges and schools of pharmacy can result in barriers to admission. While prerequisites play an important role in the admissions process and assuring student preparation, requiring excessive prerequisites can create unnecessary challenges for applicants. Prospective students may choose not to apply to a particular pharmacy school or even enter the profession because they cannot complete all course prerequisites in time to apply. Extraneous prerequisites can also contribute to the cost of education and educational indebtedness, which can more adversely affect minority and disadvantaged students. Pharmacy programs should carefully examine their course prerequisite requirements and consider new ways to measure preparedness to attract a diverse and competent pool of applicants to the profession while also being more competitive with other health profession programs.

Keywords: prerequisites, applicants, barriers, recruitment, admissions

The Accreditation Council of Pharmacy Education (ACPE) 2016 accreditation standards granted pharmacy programs latitude in determining preprofessional curricula requirements, no longer specifying a minimum of two years of prerequisite coursework compared to earlier standards. ${ }^{1}$ While the average number of semester hours required by Doctor of Pharmacy (PharmD) degree programs is 61 semester hours and equivalent to two years, the course type and requirements vary significantly. ${ }^{2}$ Prerequisite requirements represent a costly aspect of pharmacy school preparation with two years of college at a public four-year institution costing an average of approximately $\$ 50,000 .{ }^{3}$ Certainly, a foundation in core subjects is necessary for academic success in a PharmD program; but what are those core subjects? What is necessary versus beneficial? Given declining application numbers nationwide and shared goals of increasing educational access and diversity in the pharmacy profession, we strongly urge pharmacy programs to examine their prerequisite requirements with these questions in mind. ${ }^{4,5}$

Applicants face challenges when striving to fulfill course prerequisites for PharmD degree programs. Fifty-seven percent of respondents to the 2020-2021 PharmCAS Applicant Survey enrolled in an extra term during their undergraduate study to complete course prerequisites required to apply to their selected pharmacy programs, which may have increased the cost of their education. ${ }^{3,6}$ In addition, $24.9 \%$ encountered challenges in completing course prerequisites because their undergraduate institution did not offer all of the required courses. Furthermore, $27 \%$ of respondents chose not to apply to particular pharmacy programs because they could not complete one or more specific course prerequisites in time to apply, did not want to take one or more specific course prerequisites, or could not complete the required number of credit hours required in time (Table 1$)^{6}$

The variability in the number and type of course prerequisites across institutions is also a contributing barrier to pharmacy admission (Table 2). Based on the 2020-2021 AACP Summary of Course Prerequisites for Colleges and Schools of Pharmacy, no two programs require the same set of course subjects for entry into the professional PharmD degree program. Applicants who complete courses in all of the required subject areas may still be ineligible for admission to particular programs because they did not complete the specific set of courses in that area, required labs, or the minimum number of credit hours. ${ }^{2}$ While programs may allow applicants to substitute courses or choose from different prerequisite tracks, prospective students may be unaware of these policies and opt not to apply as a result. Firstgeneration, disadvantaged, and minority students may be more adversely affected by variability in pharmacy school 
prerequisites because they may have more difficulty navigating the pre-pharmacy requirements, take more time to complete course prerequisites, and have a lower tolerance for educational indebtedness and delayed income. ${ }^{7}$

In addition to variability in requirements, the number of prerequisites has increased for several programs. The percentage of pharmacy programs requiring general and organic chemistry, math, biology/biological sciences, microbiology and English have not significantly changed since 2009. A few prerequisites have declined since 2018 including communications/speech (-4\%), physics (-9\%), and economics (-12\%). However, several course requirements dramatically increased from 2009 to 2018 including anatomy and physiology, statistics, biochemistry, and sociology/psychology. The number of programs requiring these courses continued to increase in 2021 ( +3 to $+5 \%$ for anatomy and physiology, statistics, biochemistry; $+34 \%$ sociology/psychology). ${ }^{2,8}$

Academic pharmacy should review admission policies that discourage interested and competent applicants from applying to the profession. This concern is particularly valid since challenges in the pharmacy workforce and higher education landscape have had an impact on the pharmacy applicant pool during the past decade. PharmCAS application volume has decreased by $58 \%$ and the number of individual applicants applying has decreased by $24 \%$ since 2011 . The number of programs has increased from 124 during the 2010-2011 admissions cycle to 142 during the 2020-2021 admissions cycle. Between 2011 and 2021 the mean number of applications per applicant has steadily declined from 4.89 to $2.70 .{ }^{9}$ Fewer variations among course prerequisites may not be a panacea for the current admissions dilemma, but might positively contribute to institutional and national efforts to recruit students who are exploring multiple health profession programs.

ACPE Standards identify subjects that should be included in the preprofessional curricula. ${ }^{1}$ Pharmacy faculty and administrators surveyed in 2008 largely agreed coursework in core subjects should be required prior to beginning the professional program. ${ }^{10}$ Benefits of required core prerequisites include an assurance that applicants possess the foundational disciplinary knowledge necessary for success in the professional program; less expense to students than requiring the course within the professional program, which is usually at a higher tuition rate; a focus on coursework that will provide the most beneficial preparation for pharmacy school; and a common set of course grades for admission committees to evaluate during the application review process.

Many pharmacy programs have recently moved required foundational knowledge from the professional curriculum to prerequisites to focus on more advanced or specialized curricular offerings and experiential education requirements. ${ }^{11}$ This leads to rising higher education expenses that constitute a barrier for more cost-conscious students. ${ }^{12}$ Underrepresented minority students have previously identified prerequisite requirements and cost as a significant barrier to pursuing pharmacy school. ${ }^{7}$ Additionally, nontraditional students possessing undergraduate degrees may be challenged to take prerequisites not completed in previous undergraduate degree programs. The variability in prerequisite requirements between pharmacy programs require students to carefully map out requirements for each school and likely limits the programs to which they apply. ${ }^{6}$

To address the issues raised, we urge each pharmacy program to carefully examine its prerequisite requirements. Based on Table 2, prerequisites identified by $75 \%$ or more programs in 2021 as core courses necessary for success in the professional program are: biology I/II, chemistry I/II, organic chemistry I/II, anatomy/physiology, advanced math, English, and statistics. Other prerequisites should be evaluated to determine if they are barriers or keys to success. ${ }^{2}$

We recommend pharmacy programs analyze PharmD curricula to determine if prerequisites other than those listed above can be removed or categorized as recommended. Programs should also consider allowing a completed bachelor's degree in any college major prior to PharmD matriculation to fulfill non-science prerequisites and a completed bachelor's degree in specific majors (eg, biological sciences) to fulfill science prerequisites. Pharmacy programs should permit applicants to fulfill prerequisites or demonstrate competency in prerequisite subject area(s) through other means (eg, research lab or work experience; significant public speaking experience through employment; etc.) Additionally, programs should publish resources comparing their PharmD prerequisites to those in other health profession programs at their own institution to assist students considering multiple career pathways. Further, AACP should endorse this as a recommended best practice.

AACP can minimize the burden of prerequisites on applicants by continuing to compile and publish resources comparing prerequisite requirements across pharmacy programs, beginning to compile resources comparing prerequisite requirements across health programs, surveying applicants to determine the extent prerequisites influence their pharmacy school decisions, and advocating for and supporting research to determine how prerequisite requirements correlate with student performance.

While reducing prerequisite requirements has advantages for the academy, institutions may be reluctant to do so for several reasons. Barriers that may limit an institution's desire or willingness to adjust prerequisite requirements include each pharmacy program's unique characteristics that must dictate prerequisite requirements, faculty ownership of the curriculum, and resistance to change within the academy. Flexibility in course prerequisites is constrained for some 
programs by their institution's general education requirements and unique mission and strategic objectives. Workload concerns may also limit an institution's ability to carry out an evaluation of prerequisite requirements. Admissions committees may experience increased reliance on prerequisite course grades to evaluate applicant preparedness due to the increase in Pharmacy College Admission Test (PCAT) optional admissions policies. Furthermore, there is no concrete evidence that reducing prerequisites will increase the number or quality of applicants to pharmacy programs.

Individual pharmacy programs maintain unique points of excellence and curricula that are driven by faculty expertise, school mission, and stakeholders' needs. These unique aspects of individual programs present difficulties in identifying a shared list of prerequisites that meets the needs of all programs. Currently, programs require between 26 to 92 credit hours of prerequisites; this range of requirements likely reflects the unique aspects of each professional program. That said, a clear consensus is evident in the core prerequisites listed in Table 2 that are required by more than $75 \%$ of pharmacy programs. ${ }^{2}$

While concerns about the application pool might spur the conversation about reducing prerequisite requirements, faculty maintain ownership of the curriculum, and prerequisite requirements must be directly linked to each program's curriculum. Mapping course prerequisites to the professional curriculum is difficult but essential for understanding the curricular basis for each specific prerequisite, particularly when faculty perceptions of the disciplinary knowledge needed for successful completion of the professional program may vary significantly. Additionally, faculty may have perceptions on the impact that changes to prerequisites may have on the academic preparedness of entering students. Therefore, reaching faculty consensus on the appropriate prerequisite requirements within an individual pharmacy school can be difficult. Illustrating the difficulty of adopting uniform prerequisite standards is the variability among physical therapy program prerequisites, despite the American Council of Academic Physical Therapy (ACAPT) officially adopting a statement of support for a standard list of prerequisite courses. ${ }^{13,14}$ A common set of prerequisites has been identified for at least one discipline; the Council for Clinical Certification in Audiology (CFCC) and Speech-Language Pathology (SLP) defines academic coursework requirements (undergraduate and graduate) required for certification. The American Speech-Language-Hearing Association (ASHA) website describes what courses can be used to fulfill prerequisite subjects in the biological, physical, and social/behavioral sciences and statistics. ASHA guidelines are an ideal pharmacy programs should strive for and AACP should endorse this approach for providing clarity for both prospective students and institutions. ${ }^{15}$

With fewer prerequisite requirements, challenges may arise in evaluating applicants' academic preparedness for pharmacy school. For medical programs, the Medical College Admission Test (MCAT) is heavily weighted and validated as an evaluation tool for admissions, predictive of medical student performance. ${ }^{16}$ The instrument allows medical programs to limit their prerequisite course requirements and lean on MCAT preparation and grade point average (GPA) to ensure foundational disciplinary knowledge in admitted students. The dramatic decrease in pharmacy programs requiring the PCAT as an admissions requirement increases the importance of other objective measures of academic achievement, supporting arguments for keeping a broad set of prerequisite courses.

While there is limited data supporting the assertion that a high number of required prerequisites discourages applicants from applying to pharmacy programs, it is unknown whether reducing prerequisite requirements would encourage more prospective students to consider the profession. 6 Studies are needed to test these hypotheses. The challenges associated with the pharmacy applicant pool will not be completely overcome by reducing prerequisite requirements, but by doing so, the academy can encourage applications and benefit those students who do apply.

We encourage programs to review and streamline their prerequisites to remove unnecessary barriers since it is known that many applicants are not applying to programs due to barriers created by too many prerequisites. While prerequisites can provide value for programs and applicants, it is imperative in the current admissions environment to assure that programs are not creating unnecessary barriers for admission.

\section{REFERENCES}

1. American Council for Pharmacy Education. Accreditation standards and key elements for the professional program in pharmacy leading to the doctor of pharmacy degree. 2015. https://www.acpeaccredit.org/pdf/Standards2016FINAL.pdf. Accessed October 18, 2021.

2. American Association of Colleges of Pharmacy, Summary of Course Prerequisites, 2021-2022. https://www.pharmcas.org/sites/default/files/202008/Course\%20Prerequisite\%20Summary\%202020\%202021.pdf. Accessed October 18, 2021.

3. Hanson M. Cost of a College Class or Credit Hour. EducationData.org; June 25, 2021. https://educationdata.org/cost-of-a-college-class-or-credit-hour. Accessed October 18, 2021.

4. American Association of Colleges of Pharmacy, Fall 2020 Applications - Profile of Pharmacy Students; 2021. https://www.aacp.org/node/2438. Accessed October 18, 2021. 
5. American Association of Colleges of Pharmacy, 2021-2024 AACP Strategic Plan; 2021. https://www.aacp.org/article/strategic-plan. Accessed October 18, 2021.

6. American Association of Colleges of Pharmacy, 2020-2021 PharmCAS Applicant Survey Summary; 2021. https://drive.google.com/file/d/1XGwHAzAsAjTZIKhdfImQ3JHVL-82Rbte/view?usp=sharing. Accessed October 18, 2021.

7. Alonzo N, Bains A, Rhee G, Htwe K, et al. Trends in and Barriers to Enrollment of Underrepresented Minority Students in a Pharmacy School. Am J Pharm Ed. 2019;83(7)6925.

8. McLaughlin JE, Bobbitt LJ, Angelo TA, Cox WC. Content, costs, and characteristics of United States prepharmacy curricula. Curr Pharm Teach Learn. 2021;13(11):1424-1431.

9. American Association of Colleges of Pharmacy, PharmCAS Applicant Data Report, 2020-2021.

10. Broedel-Zaugg K, Buring SM, Shankar N, et al. Academic pharmacy administrators' perceptions of core requirements for entry into professional pharmacy programs. Am J Pharm Ed. 2008;72(3)52.

11. Gleason BL, Siracuse MV, Moniri NH, et al. Evolution of Preprofessional Pharmacy Curricula. Am J Pharm Ed. 2013;77(5)95.

12. Niche, 2020 Niche Senior Survey College Search to Enrollment, https://www.niche.com/about/wpcontent/uploads/2020/09/2020-Niche-Senior-Survey-College-Search-to-Enrollment.pdf. Accessed October 18, 2021.

13. American Physical Therapy Association. Comparison of Course Prerequisites by Program. https://ptcasdirectory.apta.org/5287/Comparison-of-Course-Prerequisites-by-Program. Accessed October 18, 2021.

14. American Council for Academic Physical Therapy. ACAPT Guidelines for a Successful Physical Therapy Education Program, Admissions; 2020. https://acapt.org/resources/for-program-directors\#Admissions. Accessed October 18, 2021.

15. American Speech-Language-Hearing Association, Prerequisite Course Content Areas Related to SLP Certification Standards; 2017. https://www.asha.org/certification/course-content-areas-for-slp-standards/. Accessed December 5, 2021.

16. Busche, K, Elks, ML, Hanson JT, et. al. The Validity of Scores from the New MCAT Exam in Predicting Student Performance: Results from a Multisite Study. Acad Med. 2020;95(3):387-395. 
Table 1. Reasons PharmCAS Applicants Chose Not to Apply to Selected Pharmacy Schools ${ }^{5}$

Survey Prompt: I was interested in particular pharmacy schools and later decided NOT to apply to them because...
PharmCAS Applicant Survey

Respondents

\# $\quad \%$

$183 \quad 12.8$

302

21.1

I could not complete one or more specific course prerequisites in time to apply.*

I did not want to take one or more specific course prerequisites.*

269

18.8

The school(s) required too many application materials beyond the PharmCAS application.

It would have taken me too long to complete the school-based custom questions on the PharmCAS application.

I could not afford the cost associated with applying to multiple schools.

A bachelor's degree was required for admission.

205

14.3

138

9.7

383

26.8

137

9.6

The Pharmacy College Admission Test (PCAT) was required.

I applied to all of the schools in which I was interested.

678

47.4

\begin{tabular}{l}
$\begin{array}{l}\text { Respondents who selected one or more course prerequisite } \\
\text { barriers in the pharmacy school selection process. }\end{array}$ \\
\hline
\end{tabular}

*Survey response options related to course prerequisite barriers.

$\mathrm{N}=1,429$ respondents to the $2020-2021$ PharmCAS applicant survey.

Table 2. 2021-2022 Course Prerequisites Trends for Colleges and Schools of Pharmacy ${ }^{2,8}$

\begin{tabular}{llll}
\hline Course Prerequisite Subjects & $2021(\%)^{\mathrm{a}}$ & $2018(\%)$ & $2009(\%)$ \\
\hline Chemistry & $99(-1 \%)$ & 100 & 100 \\
Math & $98(+2 \%)$ & $99(+3 \%)$ & 96 \\
Biology/Biological Science & $95(+1 \%)$ & $93(-1 \%)$ & 94 \\
English Composition / Writing & $87(+1 \%)$ & $85(-1 \%)$ & 86 \\
Anatomy, Physiology, A\&P & $82(+20 \%)$ & $77(+15 \%)$ & 62 \\
Statistics & $80(+24 \%)$ & $75(+19 \%)$ & 56 \\
\hline Microbiology & $74(+11 \%)$ & $73(+8 \%)$ & 65 \\
Communication / Speech & $67(+5 \%)$ & $71(+9 \%)$ & 62 \\
Physics & $66(-10 \%)$ & $75(-1 \%)$ & 76 \\
Social/Behavioral Science ${ }^{\mathrm{b}}$ & $60(+34 \%)$ & $26(-1 \%)$ & 27 \\
Economics & $49(-10 \%)$ & $61(+2 \%)$ & 59 \\
Humanities & 45 & $\mathrm{NR}$ & $\mathrm{NR}$ \\
General Elective(s) & 43 & $\mathrm{NR}$ & $\mathrm{NR}$ \\
Biochemistry & $32(+12 \%)$ & 29 & 20 \\
Ethics & $5(-1 \%)$ & $4(-2 \%)$ & 6 \\
Fine Arts & $\mathrm{NR}$ & 4 & 11
\end{tabular}




\begin{tabular}{llll} 
Science/Math Elective(s) & 4 & NR & NR \\
Computer Science & 2 & NR & NR \\
Foreign Language & 2 & NR & NR \\
Genetics & NR & NR & NR \\
Immunology & NR & NR & NR \\
\hline
\end{tabular}

${ }^{\mathrm{a}}$ Percent change since 2009

${ }^{\mathrm{b}}$ Social/Behavioral Science subject is inclusive of psychology and sociology courses.

Calculations include colleges and schools of pharmacy with one or more course prerequisites in the subject.

The 2018 and 2009 data do not reflect other general education requirements.

Number of colleges and schools of pharmacy in the United States: N=142 (2021), N=144 (2018), N=116 (2009). 